\title{
SATISFAÇÃO NO TRABALHO: ESTUDO LONGITUDINAL EM UMA ORGANIZAÇÃO PÚBLICA DE ENSINO SUPERIOR
}

\section{JOB SATISFACTION: A LONGITUDINAL STUDY AT A PUBLIC HIGHER EDUCATION ORGANIZATION}

\section{SATISFACCIÓN LABORAL: UN ESTUDIO LONGITUDINAL EN UNA ORGANIZACIÓN PÚBLICA DE EDUCACIÓN SUPERIOR}

\section{Jefferson Lopes La Falce}

Professor do Programa de Mestrado e Doutorado da Universidade FUMEC. Professor Orientador da Fundação Dom Cabral e consultor de Planejamento atuando no CEFET/MG

jefferson.la.falce@gmail.com

http://orcid.org/0000-0002-3293-2908

Aline De Paula Martins

Mestre em Administraçao - PDMA FUMEC

aline.pm2@gmail.com

Cristiana Fernandes De Muylder

Doutora em Economia. Professora e pesquisadora do Programa de Doutorado e Mestrado em Administração - PDMA FUMEC

cristiana.muylder@fumec.br

http://orcid.org/0000-0002-0813-0999

Daniel Jardim Pardini

Doutor em Administração . Professor do Programa de Doutorado e Mestrado em Administração da FACE-FUMEC e do Programa de Doutorado e Mestrado em Sistemas de Informação e Gestão do Conhecimento da Universidade FUMEC.

pardinidaniel@hotmail.com

http://orcid.org/0000-0003-0422-1639

\section{Editor Científico: José Edson Lara}

Organização Comitê Científico

Double Blind Review pelo SEER/OJS

Recebido em 01.11.2019

Aprovado em 08.10.2020 


\title{
Resumo
}

Objetivo: O objetivo foi analisar a evolução do nível de satisfação no trabalho dos servidores públicos de uma Instituição de Ensino Superior nos anos de 2016 e 2018, anos que tratam de mudança de carga horária na organização.

Originalidade/Lacuna: Em pesquisa bibliométrica realizada na base SPELL com os termos "satisfação no trabalho", "organização pública" e "longitudinal", não foram encontrados estudos sobre o tema.

Aspectos metodológicos: Foi realizada uma pesquisa de campo, com abordagens quantitativa e qualitativa. Os dados foram obtidos por meio de questionários utilizando a Escala da Satisfação no Trabalho (Siqueira, 2008), aplicados aos servidores públicos da organização na cidade de Belo Horizonte nos anos de 2016 e 2018. Utilizou-se ainda 6 entrevistas para entender os fatores que estariam influenciando a alteração da satisfação.

Síntese dos resultados: Os dois anos de pesquisa resultaram em indiferença por parte dos funcionários públicos. Porém, em 2018 as dimensões de satisfação com o salário, com a chefia e as promoções resultaram em insatisfação, diferentemente do primeiro ano em que os funcionários se demonstraram indiferentes em todas dimensões. A maioria dos participantes alegou que a mudança de horário implementada na instituição foi o motivador da insatisfação.

Contribuições gerenciais: É importante que gestores tenham uma visão da variação da satisfação de seus funcionários utilizando estudos longitudinais, visto que contribuem para reduzir os impactos de políticas de gestão que podem ocorrer devido à diminuição da satisfação dos funcionários, como diminuição da produtividade, rotatividade, absenteísmo, dentre outros.

Palavras-chave: Satisfação no trabalho, Triangulação, Estudo longitudinal, Instituição Pública de Ensino Superior.

\begin{abstract}
Purpose: The purpose of this this article was to analyze the evolution of the level of satisfaction in the work of public servants of a Higher Education Institution in the years 2016 and 2018, years that deal with changing the workload in the organization.
\end{abstract}

Originality/value: In a bibliometric study carried out in the SPELL database with the terms "job satisfaction", "public organization" and "longitudinal", no studies on the subject were found.

Design/method/approach: A field research was carried out, with quantitative and qualitative approaches. The data were obtained through questionnaires using the Siqueira Work Satisfaction Scale (EST) (2008), applied to public servants in the years 2016 and 2018. It was also used 6 interviews to understand the factors that would be influencing the change in job satisfaction.

Findings: The two years of research resulted in indifference on the part of public officials, that is, they were neither satisfied nor dissatisfied with the work in general. However, in 2018 the dimensions of satisfaction with salary, leadership and promotions have resulted in 
dissatisfaction, unlike the first year in which employees have been indifferent in all dimensions. Most of the participants argued that the change of schedule implemented at the institution was the motivator of job dissatisfaction.

Managerial considerations: It is important that managers have a view of the variation in the satisfaction level of their employees, allowed by the use of a longitudinal study, since in this way they can implement policies that prevent the impacts that can occur due to the decrease of employee satisfaction, such as decreased productivity, turnover, absenteeism, among others.

Key words: Job satisfaction, Triangulation, Longitudinal study, Public Institution of Higher Education.

\section{Resumen}

Objetivo: El objetivo fue analizar la evolución del nivel de satisfacción laboral de los servidores públicos de una Institución de Educación Superior en los años 2016 y 2018, años que tratan de cambiar la carga de trabajo en la organización.

Originalidad: En una encuesta bibliométrica realizada en la base de datos SPELL con los términos "satisfacción laboral", "organización pública" y "longitudinal", no se encontraron estudios sobre el tema.

Aspectos metodológicos: Se realizó una investigación de campo, con enfoques cuantitativos y cualitativos. Los datos se obtuvieron mediante cuestionarios utilizando la Escala de Satisfacción Laboral (Siqueira, 2008), aplicada a los servidores públicos de la organización en la ciudad de Belo Horizonte en los años 2016 y 2018. También se utilizaron seis entrevistas para comprender los factores que estaría influyendo en el cambio de satisfacción.

Resumen de resultados: Los dos años de investigación resultaron en indiferencia por parte de los funcionarios públicos. Sin embargo, en 2018, las dimensiones de satisfacción con salario, liderazgo y ascensos resultaron en insatisfacción, a diferencia del primer año en el que los empleados se mostraron indiferentes en todas las dimensiones. La mayoría de los participantes afirmaron que el cambio de horario implementado en la institución fue el motivo del descontento.

Contribuciones gerenciales: Es importante que los gerentes tengan una visión de la variación en la satisfacción de los empleados a través de estudios longitudinales, ya que contribuyen a reducir los impactos de las políticas de gestión que pueden ocurrir debido a la disminución de la satisfacción de los empleados, como disminución de la productividad, rotación, absentismo, entre otros.

Palabras clave: Satisfacción laboral, Triangulación, Estudio longitudinal, Institución Pública de Educación Superior. 


\section{INTRODUÇÃO}

As organizações passam por diversas transformações que afetam tanto a sociedade quanto o trabalho. $\mathrm{O}$ trabalho se relaciona com essas mudanças por se tratar de uma atividade que está presente na vida humana, organizando a vida em sociedade, estando sujeito a seu desenvolvimento (Celani-chnee, 2000). Os avanços tecnológicos trouxeram impactos para a sociedade, para as organizações públicas e privadas e para o trabalho, incluindo alterações no comportamento organizacional, tais como variações no comprometimento, na satisfação, no desempenho entre outros. Feitosa e Costa (2016) alegaram que principalmente no setor público, um dos maiores desafios é transformar o capital humano em vantagem competitiva. Ferreira (2016) afirmou que os gestores públicos precisam conhecer o que gera a satisfação dos trabalhadores no sistema público, para evitarem a insatisfação por meio de estratégias, resgatando esses funcionários antes que larguem a instituição buscando melhores condições de trabalho, redução da carga horária, autonomia, reconhecimento da chefia e segurança, dentre outras. Para a autora, a satisfação no trabalho percebida pelos trabalhadores propõe um diagnóstico situacional promissor para o serviço público.

A satisfação no trabalho é um conceito complexo e multifacetado que pode significar coisas diferentes para pessoas diferentes (Murad, Zayed \& Mukul, 2013). Os mesmos autores ainda afirmaram que a satisfação no trabalho está ligada ao sentimento de realização e sucesso de um trabalhador em seu trabalho, estando geralmente ligado à produtividade e ao bem-estar pessoal. Para os gestores é um dos temas de maiores desafios enfrentados em uma organização, pois se trata de um construto subjetivo, por depender da avaliação que o trabalhador tem sobre o seu próprio trabalho ou da realização de seus valores por meio dessa atividade (Ferreira, 2016). De acordo com Pauli, Tomasi, Gallon e Coelho (2017), uma das formas de adquirir satisfação com o trabalho é o fato de poder dominar uma atividade e ser reconhecido positivamente por procedê-la.

A organização onde a pesquisa foi realizada está situada em Belo Horizonte (MG), atua no setor educacional, com formação de nível técnico, graduação e pós-graduação, bem como pesquisa e extensão. Atuam na instituição cerca de 660 profissionais, incluindo docentes e técnicos administrativos, sendo ambos servidores públicos da esfera federal. Até 2016 o órgão possuía uma flexibilização de carga horária de 6 horas diárias e duas restantes no sistema de sobreaviso. Em 2017 esse sistema foi extinto passando o órgão a atuar em 8 horas diárias. Essa mudança de carga horária se configura uma oportunidade de pesquisa, para que se investigue o impacto na satisfação do trabalho, avaliando os anos de 2016 e 2018. 
Diante desse cenário, o presente artigo tem como objetivo analisar a evolução do nível de satisfação no trabalho dos servidores públicos da Instituição de Ensino Superior por meio de questionários aplicados no ano de 2016, comparando-os com os resultados de sua reaplicação em 2018. Embora a satisfação no trabalho seja um construto muito pesquisado, inclusive alguns estudos tenham sido realizados no serviço público (Oshagbemi, 1997; Freire, 1999; Oshagbemi, \& Hickson, 2003; Pinto \& Mariano, 2011; Lizote, Verdinelli \& Nascimento, 2017), em pesquisa bibliométrica realizada na base SPELL em agosto de 2018, com as palavras-chave "satisfação no trabalho" no título do documento, "organização pública" e "longitudinal" no resumo da base, não foram encontrados artigos que tratassem ambos os termos concomitantemente.

\section{REFERENCIAL TEÓRICO}

O conceito de satisfação no trabalho foi se transformando ao longo do tempo. Pinto e Mariano (2011) declararam que ela estava ligada apenas a questões financeiras, para somente em meados de 1940 e 1950 tem ênfase no fator humano, ou seja, passou-se a avaliar também as vontades e objetivos dos funcionários, tornando-se necessário compreender os processos que levam à satisfação dos funcionários, já que as pessoas vêm se tornando uma importante fonte de vantagem competitiva.

Com essa visão mais humana dos funcionários, as recompensas maiores passaram a ser intrínsecas, na qual eles se satisfazem mais pelo reconhecimento e autonomia em suas atividades do que com o salário em si, como notado por Handel (2005), os funcionários querem estar mais envolvidos nas decisões do local de trabalho e que aqueles que participam de programas de envolvimento dos funcionários geralmente os endossam e relatam uma maior satisfação no trabalho, autonomia e recompensas intrínsecas em média.

Segundo Marqueze e Moreno (2005) o processo de satisfação no trabalho é resultado da interação dinâmica das condições gerais de vida, das relações de trabalho, do processo de trabalho e do controle que os próprios trabalhadores possuem sobre suas condições de vida e trabalho. Sendo que ela pode ser, tanto fonte de saúde, como seu oposto, a insatisfação, pode gerar prejuízos à saúde física, mental e social, trazendo problemas à organização e ao ambiente de trabalho.

Siqueira (2008) apontou que a satisfação no trabalho tinha atenção voltada para ela desde o início do séc. XX, mas que, inicialmente, havia uma comparação entre "satisfação" e 
o "processo motivacional", sendo que a satisfação seria tratada como uma "causa" dos comportamentos no trabalho. Posteriormente, segundo a mesma autora, a satisfação passou a ser concebida como uma "atitude"; depois foi ligada à responsabilidade social, já que poderiam monitorar o quanto as empresas conseguiam promover e proteger a saúde e o bemestar dos funcionários; a partir dos anos de 1990, os conceitos foram associados a características afetivas, como estado de ânimo e emoções, estresse, burnout, sofrimento e saúde mental dos trabalhadores; passando o conceito a, no séc. XXI, ser abordado como um vínculo afetivo no indivíduo com o seu trabalho.

Siqueira (2008) definiu o conceito em cinco dimensões: salário, colegas, chefia, promoções e o próprio trabalho. Dimensões estas que o autor denominou de Escala de Satisfação no Trabalho (EST), que se trata de uma medida multidimensional composta por 25 itens com o objetivo de avaliar o nível de contentamento do trabalhador por meio dessas cinco dimensões:

- Satisfação com os colegas - contentamento com a colaboração, o amizade, o confiança e o relacionamento mentido com os colegas de trabalho;

- Satisfação com o salário - contentamento com o que recebe como salário se comparado com o quanto o indivíduo trabalha, com sua capacidade profissional, com o custo de vida e com os esforços feitos na realização do trabalho;

- Satisfação com a chefia - contentamento com a organização e capacidade profissional do chefe, com o seu interesse pelo trabalho dos subordinados e entendimento entre eles;

- Satisfação com a natureza do trabalho - contentamento com interesse despertado pelas tarefas, com a capacidade de elas absorverem o trabalhador e com a variedade das mesmas, e;

- Satisfação com as promoções - contentamento com o número de vezes que já recebeu promoções, com as garantias oferecidas a quem é promovido, com a maneira da empresa realizar promoções e com o tempo de espera pela promoção.

Posterior à breve apresentação de conceitos sobre o tema, foi realizada uma pesquisa na base Spell e Emerald no mês de Agosto de 2018, a respeito dos estudos sobre satisfação no trabalho. Buscando-se no título do documento pelo termo "satisfação no trabalho", foram encontrados 34 estudos no Brasil pela base SPELL, os quais relacionaram o construto a outras variáveis como estresse (Almeida, Tomazzoni, Santos, Rodrigues \& Simonetto, 2017; 
Almeida, Lopes, Costa \& Santos, 2018), cultura (Andrade, Limana, Estivalete \& Tanscheit, 2013; Silva, Castro \& Dos-Santos, 2018), comprometimento (Tamayo, 1998; Freire, 1999; Demo, Martins \& Roure, 2013; Cappi e Araujo, 2015; Lizote et. al., 2017), dentre outras, inclusive diagnósticos; e 11 estudos sobre diagnósticos a respeito da satisfação no trabalho na base Emerald, totalizando 45 estudos sobre o tema.

No que diz respeito à relação com o estresse, os dois estudos realizados por Almeida et. al. (2017; 2018) sobre os militares do Rio Grande do Sul demonstraram que o estresse e a satisfação no trabalho influenciam-se inversamente, ou seja, a medida que o estresse diminui, aumenta-se a satisfação percebida pelos militares, Almeida et al. (2017) analisaram as relações entre a satisfação no trabalho e o estresse ocupacional na perspectiva dos militares. Ao final do estudo mais recente, é sugerido que em pesquisas futuras não usem apenas o método quantitativo, mas também o qualitativo e realizem estudos longitudinais, visto que não foi adotado essas práticas em ambos e daria mais robustez ao estudo. A rotatividade também teve correlação com a satisfação no trabalho, negativamente, tanto no estudo com médicos, quanto com funcionários de uma multinacional (Campos \& Malik, 2008; Nodari, Bó \& Camargo, 2010), sendo que ambos estudos destacaram a capacitação como um dos fatores que mais se correlacionaram com a rotatividade e a satisfação no trabalho.

Ao contrário do estresse e da rotatividade, a cultura organizacional foi uma variável que se relacionou, em grande parte, positivamente com a satisfação dos funcionários, sendo utilizado o método quantitativo em ambos estudos (Andrade et. al., 2013; Silva et. al., 2018). Diferente de Andrade et. al. (2013), que estudou a relação direta da cultura com a satisfação no trabalho em uma instituição bancária privada após uma fusão, Silva et. al. (2018) investigou a influência do assédio moral sobre essa mesma relação, e percebeu que apenas a cultura de mercado se relacionou inversamente à satisfação, uma vez que tem relação direta com o assédio moral e este, relação inversa à satisfação.

Ao relacionar a satisfação com o comprometimento organizacional, foram encontrados estudos em empresas públicas e privadas, sendo que todos utilizaram o método quantitativo. Freire (1999) e Demo et. al. (2013) analisaram essa relação focando em aspectos da área de recursos humanos, porém enquanto Freire (1999) tratava da relação dos dois construtos como uma resposta do indivíduo à organização, para só então a área de recursos humanos tomar alguma atitude, Demo et. al. (2013) confirmaram que as políticas da área de gestão de pessoas são preditoras do comprometimento organizacional e da satisfação no trabalho. O 
Satisfação no trabalho: Estudo longitudinal em uma Organização Pública de Ensino Superior

comprometimento afetivo teve maior representatividade nos estudos e relacionou-se positivamente com a satisfação no trabalho (Tamayo, 1998; Cappi e Araujo, 2015; Lizote et. al., 2017). Cappi e Araujo (2015) além de analisarem a relação, analisaram também a forma pela qual ela antecede a intenção das gerações $\mathrm{X}$ e Y de saírem do emprego, os resultados apontaram que a geração $X$ valoriza mais a satisfação no trabalho como condição de comprometimento e manutenção na empresa do que a Y.

Outra variável estudada em relação a satisfação no trabalho é a percepção que os funcionários possuem em relação a mesma, seja em conjunto com outras variáveis ou em diagnósticos (Morgan, Mcdonagh \& Morgan, 1995; Linz, 2003; Leal, Costa, Cabral, Santos \& Pessoa, 2015; Palomino \& Frezatti, 2016; Penha, Rebouçasa, Abreua \& Parente, 2016; Ferreira, 2016; Beuren, Santos, Marques \& Resendes, 2017). No geral, com exceção dos resultados obtidos por Agapito, Santos, Alves, Sá e Santos (2014) e Lima, Zille e Soares (2015) que encontraram maior indiferença ou insatisfação dos funcionários em relação à satisfação no trabalho, os trabalhadores estão satisfeitos com seus trabalhos e sua satisfação está relacionada com justiça, ambiguidade de função, motivação, liderança, dentre outros; além dos diagnósticos. Ferreira (2016), ao contrário dos demais estudos, utilizou o método qualitativo, por meio de um estudo de caso visando conhecer de que forma os trabalhadores da saúde mental do serviço público percebiam a importância da motivação na execução do seu trabalho e em sua satisfação no trabalho. A remuneração foi destacada por alguns autores como um dos fatores que mais levam à insatisfação no trabalho (Morgan et. al., 1995; Leal et. al., 2015; Beuren et. al., 2017), diferente de Linz (2003), que obteve resultado oposto, visto que os russos, público de seu estudo, mantiveram-se satisfeitos mesmo trabalhando sem remuneração, alegando obter recompensas não monetárias, sentindo-se satisfeitos ao saber que seu trabalho contribui com a organização.

Os diagnósticos de satisfação no trabalho foram realizados em instituições públicas e privadas, sendo maior parte realizados no meio acadêmico (Oshagbemi, 1997; Oshagbemi, 1999; Oshagbemi \& Hickson, 2003; Pinto \& Mariano, 2011; Gajderowicz, Grotkowska \& Wincenciak, 2014; Leal et. al. 2015), predominando o uso do método quantitativo e tendo como objeto de estudo as universidades públicas. Enquanto a maioria dos autores buscou identificar o nível de satisfação dos professores ou características da mesma, Pinto e Mariano (2011) procuraram entender os fatores que levavam à satisfação dos administradores escolares, notando que o orgulho de trabalhar nas melhores escolas, o clima de camaradagem e o trabalho em equipe são os fatores que mais contribuem para aumentar os níveis de 
satisfação dos funcionários. Leal et. al. (2015) corroboraram com estudo de Oshagbemi and Hickson (2003), uma vez que ambos destacaram a remuneração como fator de insatisfação no serviço educacional público, sendo que Oshagbemi and Hickson (2003) notaram que as mulheres no geral são mais satisfeitas com seu salário do que os homens. Gajderowicz et. al. (2014), no âmbito educacional, foram os únicos autores que destacaram a perspectiva dos graduados, diferente dos estudos anteriores, uma vez que se preocuparam com as carreiras de graduados do ensino superior. A tabela 1 sintetiza todos os estudos destacados acima:

\section{Tabela 1}

Síntese de estudos sobre satisfação no trabalho

\begin{tabular}{|l|l|}
\hline Temática do artigo & Autores \\
\hline Diagnóstico de satisfação & $\begin{array}{l}\text { Morgan et. al., (1995); Oshagbemi, (1997); Oshagbemi, (1999); Oshagbemi } \\
\text { and Hickson, (2003); Linz, (2003); Pinto e Mariano, (2011); Gajderowicz et. } \\
\text { al., (2014); Agapito et. al., (2014); Leal et. al. (2015); Lima et. al., (2015); } \\
\text { Palomino e Frezatti, (2016); Penha et. al., (2016). }\end{array}$ \\
\hline Relação de satisfação com estresse & Almeida et. al. (2017:2018). \\
\hline Satisfação e rotatividade & Campos e Malik, (2008); Nodari et. al., (2010). \\
\hline Relação de satisfação com cultura & Andrade et. al., (2013); Silva et. al., (2018). \\
\hline Comprometimento e satisfação & $\begin{array}{l}\text { Tamayo, (1998); Freire, (1999); Demo et. al, (2013); Cappi e Araujo, (2015); } \\
\text { Lizote et. al., (2017). }\end{array}$ \\
& \\
&
\end{tabular}

Fonte: elaborada pelos autores.

A seguir serão traçadas as considerações metodológicas.

\section{PROCEDIMENTO METODOLÓGICO}

Este trabalho caracteriza-se como uma pesquisa descritiva, comparativa e longitudinal de coorte no que concerne ao horizonte temporal, já que funcionários de uma mesma instituição responderam questionários dentro de um espaço de 2 anos e, de acordo com Vergara (2016), esse tipo de pesquisa é realizada em diferentes momentos, quando precisa-se descobrir se ocorreram mudanças do fenômeno estudado no tempo.

Já em relação aos meios de pesquisa, no que se refere ao ambiente em que os dados são coletados, essa pesquisa é elaborada por meio de uma pesquisa de campo. No que diz respeito à natureza dos dados, essa pesquisa adotou o procedimento da triangulação, que 
utiliza métodos múltiplos, para assegurar uma compreensão profunda do fenômeno em questão, exibindo múltiplas realidades refratadas simultaneamente (Triviños, 1987).

A população selecionada para a pesquisa se trata de uma instituição de ensino superior que, em 2018, reúne 353 técnicos administrativos, o que demonstra um pequeno aumento no quadro de funcionários em relação ao primeiro ano do estudo, 2016, cujo total de técnicos administrativos era de 337 servidores. Foram enviados questionários a todos os servidores técnicos.

Os dados foram coletados em duas etapas, devido ao procedimento da triangulação (Triviños, 1987), sendo na primeira etapa a aplicação de questionários, utilizada para coletar os dados quantitativos. Para o presente estudo, optou-se pela utilização do modelo EST de Siqueira (2008), que possui uma escala do tipo Likert de sete pontos, variando de 1 (totalmente insatisfeito) a 7 (totalmente satisfeito).

Para coletar os dados qualitativos, de forma a entender e aprofundar os resultados encontrados com os dados quantitativos, foram realizadas seis entrevistas com servidores públicos da instituição, sendo 3 com perfil de gestor e 3 da área técnica. As questões foram elaboradas para aprofundar os resultados da etapa quantitativa para identificar os fatores e variáveis que alteraram a percepção da satisfação do trabalho.

A técnica de análise de dados também foi realizada em duas etapas, sendo primeiramente analisado os dados quantitativos, por meio da estatística descritiva uni e bivariada, sendo empregados os testes não paramétricos de comparação de médias de MannWhitney para amostras independente. O teste não paramétrico de correlação linear de Spearman foi utilizado a fim de averiguar o grau de correlação entre as variáveis demográficas, profissionais e as dimensões de satisfação. Utilizou-se o software SPSS na versão 25 .

Em seguida foi realizada a análise das entrevistas por meio de uma análise do conteúdo, onde as falas dos entrevistados foram analisadas e articuladas com a teoria de satisfação no trabalho.

\section{RESULTADOS E ANÁLISES}

A pesquisa elaborada na instituição contou com a colaboração de 79 participantes no ano de 2016 e 84 participantes em 2018. Em 2016, houve maior participação do sexo 
masculino, com 44 de participantes representando 55\% do total e, $25 \%$ dos respondentes tinham entre 56 e 60 anos de idade, apesar de ter concentração significativa de participantes entre 41 a 45 anos e 31 a 35 anos, contando com 15\% em cada faixa etária. Em relação ao estado civil dos participantes, praticamente $50 \%$ dos funcionários encontram-se na categoria "casados", apesar de não ser tão destoante do número de pessoas solteiras, que conta com $40 \%$. Contatou-se ainda que que $83 \%$ possui especialização ou mestrado. Já no que se refere aos dados profissionais há uma predominância de funcionários que já trabalham na instituição há mais de 20 anos e também na parcela que atuam no cargo há mais de 20 anos, ou seja, pode-se afirmar que no geral os funcionários públicos tendem a permanecer no serviço público, até mesmo devido à estabilidade e no caso, se mantiveram no mesmo cargo durante os anos de trabalho.

Os resultados do ano de 2018 mostram que, ao contrário do primeiro ano de pesquisa, a maioria dos respondentes são do sexo feminino, contando com 39 respondentes que representam $46 \%$ do total em 2018, mas continua prevalecendo maior participação de funcionários com idade entre 56 e 60 anos. A maioria dos candidatos também são casados, somando $40 \%$ do total, e prevalece com pouca diferença em relação aos solteiros com 33\% do total. $51 \%$ dos respondentes tem especialização, seguido por $27 \%$ com mestrado. Com relação aos dados profissionais, mantém-se o resultado do primeiro ano, obtendo a maioria dos funcionários mais de 20 anos na instituição. Em relação ao tempo no cargo, 23\% tem apenas de 2 a 5 anos, seguido do tempo de 10 a 15 anos, correspondendo a $21 \%$.

A tabela 2 apresenta os resultados de satisfação da coleta realizada na organização em 2016 tratadas no modelo de Siqueira (2008), destacando o número de respondentes que se declararam insatisfeitos, indiferentes e satisfeitos com relação às dimensões: 
Tabela 2

Médias e Medianas das Dimensões de Satisfação em 2016

\begin{tabular}{lccccc}
\multicolumn{1}{c}{ Dimensões } & Média & Mediana & Insatisfação & Indiferença & Satisfação \\
\hline Satisfação com Colegas & 4,80 & 4,75 & 8 & 69 & 2 \\
\hline Satisfação com salário & 4,48 & 4,60 & 22 & 52 & 5 \\
\hline Satisfação com chefia & 4,01 & 4,00 & 34 & 32 & 41 \\
\hline Satisfação com a natureza do trabalho & 4,94 & 5,00 & 7 & 31 & 18 \\
& & & & & \\
\hline Satisfação com as promoções & 4,25 & 4,20 & 23 & \\
\hline
\end{tabular}

Fonte: Dados da pesquisa (2018).

De acordo com Siqueira (2008), quanto maior for o valor do escore médio, maior seria o grau de contentamento ou satisfação do empregado com a dimensão em análise. Portanto, os valores obtidos entre 1 e 3,9 tendem a apontar insatisfação, enquanto os valores entre 4 e 4,9 informam um estado de indiferença e, entre 5 e 7, tendem a indicar satisfação. No que tange à satisfação no trabalho, nota-se que em 2016 as médias das cinco dimensões foram superiores a 4,00, mas inferiores a 5,00, indicando que a maioria dos respondentes se sentem indiferentes quanto às mesmas, confirmando os resultados encontrados por Agapito et. al. (2014), Lima et. al. (2015) e Andrade, Costa, Estivalete e Lengler (2017) na dimensão da satisfação com os colegas, que se demonstraram indiferentes em relação ao espírito de colaboração, com o tipo de amizade, e com a confiança que os funcionários podem ter com os seus colegas. Porém, diferentemente das demais, a dimensão "satisfação com a natureza do trabalho" obteve sua média acima de 4,9 indicando satisfação dos funcionários em sua relação, confirmado pelo maior número de funcionários que se encontram no quadrante de "satisfeitos" como resultado, corroborando com gestores escolares da rede pública nos resultados encontrados por Pinto e Mariano (2011), que estão satisfeitos com a realização de seu trabalho e possibilidade de variação nas atividades executadas.

O mesmo não ocorre com a dimensão "satisfação com a chefia", visto que apesar da maior parte dos funcionários estarem indiferentes quanto a satisfação no trabalho, nessa dimensão há uma predominância de participantes insatisfeitos mesmo que a média se enquadre como indiferente, corroborando com os resultados encontrados por Pinto e Mariano (2011), que ao estudar o nível de satisfação de funcionários da rede pública e privada, 
constaram que apenas cerca de 35\% de ambos respondentes encontram-se satisfeitos com seus chefes, onde mesmo trabalhando em uma organização pública, na qual ao menos com relação à cultura brasileira, difunde-se a estabilidade e a quase impossibilidade de que o sujeito seja removido, ainda assim, os colaboradores não se sentem à vontade para discordar dos seus superiores. Porém, resultado oposto foi encontrado por Marques, Borges e Reis (2016) ao buscar compreender as implicações da mudança organizacional nos níveis de satisfação no trabalho, a partir das reações individuais à mudança realizando um survey no governo de Minas Gerais com 679 servidores públicos, onde notaram que os servidores encontram-se satisfeitos ou muito satisfeitos com suas chefias, totalizando $81,6 \%$ da população de servidores.

A tabela 3 apresenta os resultados obtidos no ano de 2018:

\section{Tabela 3}

Médias e Medianas das Dimensões de Satisfação em 2018

\begin{tabular}{|c|c|c|c|c|c|}
\hline Dimensões & Média & Mediana & Insatisfação & Indiferença & Satisfação \\
\hline Satisfação com Colegas & 4,30 & 4,25 & 25 & 31 & 28 \\
\hline Satisfação com salário & 3,98 & 4,00 & 34 & 44 & 6 \\
\hline Satisfação com chefia & 3,90 & 4,00 & 36 & 34 & 14 \\
\hline $\begin{array}{l}\text { Satisfação com a natureza do } \\
\text { trabalho }\end{array}$ & 4,02 & 4,40 & 32 & 22 & 30 \\
\hline Satisfação com as promoções & 3,82 & 4,00 & 41 & 29 & 14 \\
\hline
\end{tabular}

Fonte: Dados da pesquisa (2018).

No ano de 2018 os resultados foram diferentes, visto que as dimensões "satisfação com salário", "satisfação com chefia" e "satisfação com as promoções" tiveram suas médias abaixo de 4,0, o que significa maior insatisfação dos funcionários com tais dimensões, corroborando com resultado encontrando por Agapito et. al. (2014) e Andrade et. al. (2017) quanto às dimensões salário e promoções; e as outras duas dimensões maiores que 4,0, correspondendo a indiferença, assim como no resultado obtido por Lima et. al. (2015), sendo que nenhuma dimensão obteve satisfeito como resultado. Porém, observando as medianas e separadamente os respondentes em cada estado de satisfação, pode-se notar maior nível de 
Satisfação no trabalho: Estudo longitudinal em uma Organização Pública de Ensino Superior

indiferença quanto às dimensões. Mesmo que o ano de 2018 tenha apresentado uma diminuição no nível de satisfação dos funcionários com relação a 2016, a média final da satisfação no trabalho manteve-se como "indiferença", conforme será destacado na Tabela 4.

A dimensão "satisfação com salário" embora tenha média que demonstre insatisfação dos funcionários, teve a maioria dos respondentes no quadrante "indiferença", declarando-se indiferentes quanto à satisfação de seus salários, sendo evidenciado apenas pela mediana com resultado 4,0 não estando alinhado a maioria dos resultados na rede pública que destacam o salário como a dimensão de maior insatisfação por parte de funcionários públicos (Oshagbemi \& Hickson, 2003; Pinto e Mariano, 2011; Leal, 2015; Marques et. al., 2016). Oshagbemi and Hickson (2003) ao analisar o grau de satisfação dos acadêmicos britânicos com suas tarefas primárias de ensino e pesquisa e com seus salários ainda revelaram que uma possibilidade é que essa insatisfação seja uma consequência direta da crescente desigualdade salarial dos salários acadêmicos com os recebidos por seus companheiros empregados na indústria privada. A satisfação com os colegas foi o maior escore médio no ano de 2018, alinhado com Pinto e Mariano (2011), visto que para eles, os respondentes da rede pública possuem grande satisfação com o trabalho em equipe e clima de camaradagem na instituição em que trabalham.

No que diz respeito a estatística bivariada, para detectar possíveis diferenças dos participantes no ano de 2016 e em 2018, os resultados mostraram diferenças estatisticamente significativas em 4 dimensões destacadas na Tabela 4 abaixo:

\section{Tabela 4}

Resultado da análise comparativa de 2016 e 2018

\begin{tabular}{lccccc}
\hline \multicolumn{1}{c}{ Dimensões } & $\mathbf{2 0 1 6}$ & $\mathbf{2 0 1 8}$ & P valor & Efeito d=cohen \\
\hline Satisfação com Colegas & 4,75 & 4,25 & $\mathbf{0 , 0 0 3}$ & $2016>2018$ & 0,482 (ETA SQ 0,055) \\
& & & & & \\
\hline Satisfação com salário & 4,60 & 4,00 & $\mathbf{0 , 0 0 3}$ & $2016>2018$ & 0,475 (ETA SQ 0,053) \\
\hline Satisfação com chefia & 4,00 & 4,00 & 0,498 & & \\
\hline $\begin{array}{l}\text { Satisfação com a natureza do } \\
\text { trabalho }\end{array}$ & 5,00 & 4,40 & $\mathbf{0 , 0 0 1}$ & $2016>2018$ & 0,556 (ETA SQ 0,072) \\
\hline $\begin{array}{l}\text { Satisfação com as promoções } \\
\text { Fonte: Dados da pesquisa (2018). }\end{array}$ & 4,20 & 4,00 & $\mathbf{0 , 0 2 1}$ & $2016>2018$ & 0,365 (ETA SQ 0.032) \\
\hline
\end{tabular}

Fonte: Dados da pesquisa (2018). 
Os resultados obtidos em 2018 demonstraram menor satisfação dos funcionários em relação a 2016, com exceção da dimensão "satisfação com chefia" que não obteve alteração. Assim sendo, nas dimensões satisfação com colegas, com salário, com a natureza do trabalho e com as promoções houve redução da percepção dos funcionários. Estes resultados indicam que as políticas internas da organização e questões voltadas para gestão de pessoas não estão atendendo às necessidades dos trabalhadores. Por se tratar de uma organização pública questiona-se os impactos na produtividade de qualidade da prestação do serviço, devendo estes resultados serem motivo de atenção dos gestores. Importante destacar que o estudo longitudinal se mostra relevante para indicar alterações nos níveis de satisfação ao longo dos anos, fato também já descrito por La Falce, Paiva, Muylder e Morais (2017).

\subsection{Resultados da Etapa Qualitativa}

Participaram da etapa qualitativa, 6 técnicos da Organização, sendo 3 com perfil de Gestor e 3 com perfil técnico. Destaca-se que todos os participantes pediram que não fossem identificados. Este receio e medo de identificação chama a atenção dos pesquisadores por indicar um possível cenário de retaliação na organização. Para atender ao pedido de não identificação, os entrevistados serão tratados como Gestor 1, Gestor 2, Gestor 3, Técnico 1, Técnico 2 e Técnico 3.

A primeira pergunta da entrevista tratava dos fatores que levavam a alterações da satisfação na instituição, no geral os entrevistados destacaram a alteração da carga horária no trabalho, a falta de reconhecimento pelos supervisores, a falta de regulamentação dos afastamentos, conflitos entre gerações de servidores, dentre outros. O principal motivo abordado foi a alteração na carga horária, inclusive uma maior rigidez para controle da mesma por parte de órgãos de fiscalização, como alegou o Gestor 3:

"Nós tínhamos um horário reduzido que era negociado ainda, agora passou a ser rígido em vista do que estava."

Outro fator atrelado a mudança da carga horária aumentada, seriam as atividades realizadas pelo aumento para 1 hora de almoço, onde alguns funcionários almoçavam na instituição em pouco tempo e acabavam trabalhando em hora de descanso, conforme afirmou o Gestor 2: 
"Outra coisa, agora com 9 horas você tem uma hora de almoço, onde eu fico o resto do tempo? Você acaba trabalhando também, então deveriam pensar em um local de convivência."

Outros autores destacaram o horário de trabalho como um fator que altera a satisfação dos funcionários, mesmo que de forma diferente da carga horaria como no caso de Andrade, Pereira e Ckagnazaroff (2007), ao descrever fatores que contribuem para satisfação e insatisfação no trabalho em um estudo de caso com três empresas de prestação de serviço situadas no estado de Minas Gerais. Os autores encontraram que em duas das empresas estudadas, os funcionários destacam várias vezes o horário de trabalho como fator negativo. Já no estudo de Pinto e Mariano (2011), notou-se que apenas 6,7\% dos participantes da rede pública demonstraram-se satisfeitos com o horário de trabalho e somente 11,6\% acreditam que a carga de trabalho seja adequada.

Quando indagados a respeito de políticas de reconhecimento e valorização dos funcionários na instituição, a maioria desconhece políticas nesse sentido, e outros acreditam que sejam implantadas de acordo com a política imediata, sendo que apenas um entrevistado declarou sentir-se reconhecido por parte de sua chefia, opondo-se aos resultados obtidos por Pinto e Mariano (2011), que constataram que 66,7\% dos gestores da rede pública possuem maior percepção de reconhecimento entre seus colegas, além de 97,7\% dos participantes da rede pública terem afirmado que seu trabalho os realiza. O Gestor 3 por exemplo, destacou haver subjetividade na avaliação direta de chefias, conforme destacado a seguir:

"A instituição tem sim esse trabalho, mas ele é distribuído dentro da estrutura administrativa e nem sempre é justo, então esse gerenciamento ocorre dentro das chefias imediatas que nem sempre são iguais."

Andrade et. al. (2007) já destacava que os empregados necessitam de reconhecimento e valorização, seja onde trabalham ou onde venham a trabalhar futuramente. Isto mostra que a organização pesquisada não tem políticas adequadas e necessita uma revisão neste sentido.

É importante que haja investimento em uma gestão proativa, que institua programas de treinamento, capacitação e desenvolvimento (Correa, Camelo \& Leal, 2017), e apenas o Gestor 1 destacou um projeto que ainda está em fase de implementação, o qual consiste em, segundo ele:

“... hoje existe essa politica de RH que envolve treinamento, mapeamento das atividades, de gestão de competências. Há apenas um projeto de implantação, entre a ideia e a pratica ainda há um longo caminho a ser percorrido, mas é uma luz no fim do túnel." 
Em relação aos controles exercidos sobre os funcionários, é citado apenas o registro de ponto eletrônico, que inclusive de acordo com o Gestor 1, tem ficado mais rígido após a mudança da carga horária:

"O controle estava previsto, porque o regime de horas de trabalho mudou de uns anos pra cá e houve maior controle da controladoria sobre o horário de trabalho, está mais rígido agora."

Além disso, alguns citaram que apesar do controle do horário pelo ponto, não há exatamente um controle de produtividade, e apenas no horário em si, o que acaba gerando insatisfação em alguns funcionários, como percebe-se pela resposta do Técnico 2:

"No geral: existe uma certa insatisfação, entre a discrepância entre ponto eletrônico e produtividade, não sei se tem preocupação institucional de promover a produtividade para além do mero controle do tempo, pelo fato da instituição estar respondendo processos, existe preocupação com o horário, mais do que produtividade."

No que diz respeito ao desenvolvimento de carreira na instituição, alguns desconhecem atitudes da mesma com relação a carreira, um deles cita um programa da instituição e outros citam a progressão, e oportunidade de crescimento principalmente com títulos, sendo que o Gestor 3 ainda acrescenta que a instituição gera oportunidades para quem está interessado, quando responde:

"No geral, os servidores, ela é vinculada a uma questão de politica de governo, então dentro da legislação, o CEFET está mais adiante, da amparo e possibilidades da pessoa melhorar dentro da carreira, o CEFET sempre apoiou, hoje o patamar que a legislação permite, quem não subiu aqui dentro é porque não quis, porque os que perceberam a oportunidade tiveram apoio e conseguiram esse resultado."

Quanto a programas de suporte social, que envolvam a família, e vida social dos servidores fora do ambiente de trabalho, a maioria desconhece algum programa nesse sentido, sendo que apenas um deles, o Gestor 3 , citou conhecer algum tipo de política, entretanto afirma que é feito de uma maneira não estruturada. Esse é um fator que pode influenciar a maneira como o funcionário desempenha suas atividades, uma vez que Correa et. al. (2017), afirmaram que quando os empregados reconhecem o apoio de seus empregadores em causas sociais e ambientais, os trabalhadores melhoram suas atitudes no local de trabalho. Já a pergunta sobre o ambiente físico gerou controvérsias, visto que alguns citaram que não existe e, pelo contrário, piorou, e outros disseram que mesmo sem uma política explícita, puderam observar melhoras significativas no ambiente. 
Por último os participantes foram questionados a respeito da comunicação dentro da instituição, obtendo respostas praticamente iguais, sendo que todos alegaram haver certa falta de comunicação interna, ou ao menos falha em alguns aspectos. Inclusive dois entrevistados Técnico 2 e 3 (Homem/Mulher) abordaram a questão específica da mudança de horário relacionando a mesma com controle e comunicação quando afirmaram:

"H: é meio falha, como quando colocaram, mudaram pra passar o cartão na entrada, não avisaram ninguém... É informal.

M: Passaram dois dias, mandaram falar... a comunicação não é eficiente."

Ou seja, mesmo que eles tenham citado o email como instrumento formal de comunicação, existe ainda muita informalidade e falta de comunicação em alguns aspectos dentro da instituição. Alguns estudos destacaram a falta de comunicação como um fator que afeta a satisfação dos funcionários (Pinto \& Mariano, 2011; Marques et. al., 2016; Correa et. al., 2017). Isto indica a necessidade de um olhar mais atento para questões da comunicação formal para os trabalhadores da organização.

Para Freire (1999), algumas variáveis que podem interferir na satisfação dos funcionários, além do comprometimento, são a falta de relacionamento na equipe; o descumprimento de etapas e metas do projeto de trabalho; a burocracia; a falta de reconhecimento do trabalho; as condições de trabalho; e o gerenciamento organizacional. Neste sentido, pôde-se observar que os entrevistados no geral não conhecem políticas que incentivem o reconhecimento na instituição, como foi destacado pelo Gestor 2 quando questionado sobre tais políticas:

"Não vejo isso... eu tenho escutado muita crítica, nenhum elogio. Percebo da direção da instituição é que a gente não é elogiado... Não sei se meu serviço pode ser melhorado ou não, ta tudo ruim."

O resultado encontrado no presente estudo corrobora em alguns aspectos com o estudo de Andrade et. al. (2013), que comparou o nível de satisfação dos funcionários em uma instituição bancária antes e após uma fusão, sendo que todos $\mathrm{P}$ valor foram significativos e na segunda situação comparada, que no caso foi após a fusão, todas as médias foram menores. Porém, diferentemente do estudo presente, Andrade et. al. (2013) encontraram também significância na dimensão "satisfação com a chefia" e não destacaram a significância com relação a "natureza do trabalho". Ou seja, houve um fato que desencadeou uma mudança percebida no nível de satisfação dos funcionários, que no caso de Andrade et. al. (2013) foi a fusão na instituição e, no presente estudo, de acordo com a Tabela 4, a média geral de todas as 
dimensões teve uma diminuição de 0,5 no nível de satisfação no trabalho dos funcionários de 2016 para 2018, sendo que de acordo com Marques et. al. (2016), a forma em que uma mudança é realizada influencia diretamente na satisfação dos funcionários, a mudança na carga horaria implantada em 2017 pode ter ocasionado essa diminuição no nível de satisfação dos servidores da instituição, uma vez que em 2016 essa carga era de 6 horas e em 2017 passou para 8 horas. Portanto os funcionários teriam ficado insatisfeitos com a mudança e, mesmo que não haja uma dimensão que evidencie explicitamente a carga horaria no trabalho, a que se aproxima mais dessa relação seria com a natureza do trabalho por tratar do grau de interesse nas tarefas, as preocupações exigidas e variedade de tarefas realizadas por exemplo, sendo justamente a que obteve maior significância.

A insatisfação com o horário de trabalho na rede pública daria respaldo ao resultado encontrado por Pinto e Mariano (2011), uma vez que para os autores, ao analisar a satisfação na rede pública e privada, destacaram que apesar da rede pública ter obtido níveis elevados de satisfação, somente $6,7 \%$ dos respondentes afirmaram estar totalmente satisfeitos com o horário de trabalho e apenas $11,6 \%$ creem que a carga de trabalho seja adequada.

A seguir as considerações finais.

\section{CONSIDERAÇÕES FINAIS}

O objetivo do artigo foi analisar a evolução do nível de satisfação no trabalho dos servidores públicos de uma Instituição de Ensino Superior nos anos de 2016 e 2018. Para atingir o objetivo, foi adotada como metodologia descritiva, por meio de uma pesquisa de campo, utilizando abordagens quantitativas e qualitativas. Para tal aplicou-se um questionário proposto por Siqueira (2008) e entrevistas realizadas com 6 servidores públicos.

Com os dados coletados por meio do método quantitativo, foi possível perceber que o nível de satisfação das dimensões da satisfação com os colegas, com o salário, com a natureza do trabalho e com as promoções diminuiu no ano de 2018, ficando apenas a dimensão satisfação com a chefia sem alteração. Além disso, nota-se que apenas a satisfação com a natureza do trabalho em 2016 resultou em satisfação dos funcionários, visto que em todas as outras médias das dimensões, eles estão indiferentes quanto a sua satisfação. Os resultados evidenciam um fator preocupante para os gestores, pois nota-se que além de os funcionários estarem mais indiferentes do que satisfeitos com dimensões no trabalho, o nível ter diminuído na maioria delas pode impactar em diminuição na produção por parte dos funcionários, 
rotatividade, absenteísmo, e analisar esse nível constantemente é importante para auxiliar os gestores no momento de implementar uma política que incentive a satisfação de seus funcionários.

Os resultados da etapa qualitativa evidenciaram que a mudança ocorrida na instituição em relação a carga horária, que teve um aumento de 2 horas a partir de 2017, a falha na comunicação interna da instituição, ausência de políticas de reconhecimento, capacitação e suporte social, implementação de um controle rígido na jornada de horas trabalhadas tem se configurado variáveis responsáveis pela redução da satisfação na organização.

Devido aos trabalhadores serem a vantagem competitiva das organizações, eles impactam na sua produtividade e resultados, é essencial que os gestores compreendam a importância de manter seus funcionários satisfeitos, sendo possível a visualização da variação do nível de satisfação por meio de estudos longitudinais, para que possam realizar monitoramento e avaliação adequada desses níveis e, posteriormente implementarem estratégias que promovam a satisfação. Isso faz com que o estudo contribua academicamente por preencher a lacuna na literatura que sugere estudos longitudinais. Este estudo também mostra que análises quantitativas e qualitativas são fundamentais para uma melhor compreensão de um fenômeno, no caso da satisfação do trabalho.

Em síntese percebeu-se que variações na carga horária de trabalho, ausência de políticas estruturadas e difundidas sobre reconhecimento, plano de carreira, capacitações e treinamento possuem impacto na satisfação, bem como relação com a redução desta no último ano pesquisado, 2018. Este estudo indica que além dos diagnósticos constantes por meio de estudos longitudinais são necessárias analises de outras variáveis do contexto para entender as alterações ao longo dos anos. Também se destaca a importância das políticas de gestão de pessoas para a manutenção da satisfação, produtividade e qualidade do atendimento em serviços públicos.

No que se refere a implicações práticas, este estudo mostra que os gestores precisam analisar os impactos das políticas e ações de gestões de pessoas para a manutenção ou melhoria dos níveis de satisfação no trabalho.

Como limitações do estudo, destaca-se a abordagem em apenas uma organização, não sendo possível generalizações. Sugere-se assim pesquisas em outras organizações de natureza pública e privada, com a perspectiva longitudinal a fim de confirmar os resultados obtidos aqui, para propiciar uma ampliação das pesquisas envolvendo a satisfação dos funcionários, inclusive que comparem diferentes cargos ou contratos de trabalho, visto que é um construto 
que influencia não somente o profissional, mas também a organização como um todo, por afetar a rotatividade e a produtividade da mesma.

\section{REFERENCIAS}

Agapito, P. R.; Santos, C. B. D.; Alves, C. H.; Sá, C. R. C. B.; \& Santos, H. R. D. (2014). Análise da satisfação no trabalho e do cumprimento dos contratos psicológicos dos profissionais da Região do ABC Paulista. Revista Eletrônica Gestão e Serviços, 5(1), 766786.

Almeida, D. M.; Lopes, L. F. D.; Costa, V. M. F.; \& Santos, R. C. T. D. (2018). Policiais Militares do Estado do RS: Relação entre Satisfação no Trabalho e Estresse Ocupacional. Administração Pública e Gestão Social, 10(1), 55-65.

Almeida, D. M.; Tomazzoni, G. C.; Santos, A. S. D.; Rodrigues, G. O.; \& Simonetto, E. O. (2017). Análise de Cenários Envolvendo Satisfação no Trabalho e Estresse Ocupacional por meio da Dinâmica de Sistemas. Future Studies Research Journal: Trends and Strategies, 9(1), 78-94.

Andrade, C. R.; Pereira, L. Z.; \& Ckagnazaroff, I. B. (2007). Elementos de satisfação e insatisfação no trabalho operacional: revisitando Herzberg. Revista Gestão \& Tecnologia, 7(1), 67-89.

Andrade, T.; Costa, V. F.; Estivalete, V. F. B.; \& Lengler, L. (2017). Comportamento de Cidadania Organizacional: Um Olhar à Luz dos Valores e da Satisfação no Trabalho. Revista Brasileira de Gestão de Negócios, 19(64), 236-262.

Andrade, T.; Limana, S.; Estivalete, V. F. B.; \& Tanscheit, F. (2013). Cultura organizacional e satisfação no trabalho sob a percepção dos colaboradores de uma instituição bancária após o processo de fusão. Revista Administração em Diálogo, 15(2), 52-78.

Beuren, I. M.; Santos, V. D.; Marques, L.; \& Resendes, M. (2017). Relação entre Percepção de Justiça Organizacional e Satisfação no Trabalho. Revista de Educação e Pesquisa em Contabilidade, 11, 69-86.

Campos, C. V. A.; \& Malik, A. M. (2008). Satisfação no trabalho e rotatividade dos médicos do Programa de Saúde da Família. Revista de Administração Pública, 42(2), 347-368.

Cappi, M. N.; \& Araujo, B. F. V. B. (2015). Satisfação no Trabalho, Comprometimento Organizacional e Intenção de Sair: um Estudo Entre as Gerações X e Y. REAd. Revista Eletrônica de Administração, 21(3), 576-600.

Celani-Chnee, P. C. (2000). Trabalho e mudanças na organização. Pensamento \& Realidade, 7(1), 3-14.

Correa, R.; Camelo, S. H. H.; \& Leal, L. A. (2017). Satisfação no Trabalho dos Bancários e seus Fatores Determinantes - Uma Revisão Integrativa . Revista Economia \& Gestão, 17(47), 65-84.

Demo, G.; Martins, P. R.; \& Roure, P. (2013). Políticas de gestão de pessoas, comprometimento organizacional e satisfação no trabalho na Livraria Cultura. Revista Alcance, 20(2), 237-254.

Feitosa, L. V. D. S., \& Costa, C.E.S.D. (2016). Inovações no setor público: A resistência à mudança e o impacto causado no comportamento do indivíduo. Anais do V SINGEP. São Paulo. 
Ferreira, C. A. (2016). A.Percepção da Motivação e Satisfação no Trabalho pelos Trabalhadores de uma Instituição Psiquiátrica no Brasil. Revista Capital Científico Eletrônica, 14(2), 25-41.

Freire, J. R. (1999). Comprometimento organizacional e satisfação no trabalho: uma análise da gestão de recursos humanos. Revista Administração em Diálogo, 1(1), 1-19.

Gajderowicz, T.; Grotkowska, G.; \& Wincenciak, L. (2014). Graduates' job satisfaction across domains of study. International Journal of Manpower, 35(4), 470-499.

Handel, M. J. (2005). Trends in Perceived Job Quality, 1989 to 1998. Work and occupations, 32(1), 66-94.

La Falce, J. L.; Paiva, K. C. M.; Muylder, C. F.; \& Morais, M. M. D. S. (2017). Organizational Commitment: Longitudinal Study in a Public Higher Education Organization. Revista de Administração Mackenzie, 18(6), 124-148.

Leal, P. H.; Costa, B. M. N.; Cabral, A. C. A.; Santos, S. M. D.; \& Pessoa, M. N. M. (2015). Satisfação no Trabalho: um Estudo na Universidade do Estado do Rio Grande do Norte. RAUnP - Revista Eletrônica do Mestrado Profissional em Administração da Universidade Potiguar, 7(2), 106-120.

Lima, A. J.; Zille, L. P.; \& Soares, M. G. (2015). Um Olhar sobre a Satisfação no Trabalho: estudo em Organização Multinacional do Setor de Usinagem no Estado de Minas Gerais. Revista Gestão \& Planejamento, 16(3), 310-325.

Linz, S. J. (2003). Job satisfaction among Russian workers. International Journal of Manpower, 24(6), 626-652.

Lizote, S. A.; Verdinelli, M. A.; \& Nascimento, S. (2017). Relação do Comprometimento Organizacional e da Satisfação no Trabalho de Funcionários Públicos Municipais. Revista de Administração Pública, 51(6), 947-967

Marques, A. L.; Borges, R.; \& Reis, I. C. (2016). Mudança organizacional e satisfação no trabalho: um estudo com servidores públicos do estado de Minas Gerais. Rev. Adm. Pública, 50(1), 41-58.

Marqueze, E. C.; \& Moreno, C. R. C. (2005). Satisfação no trabalho - uma breve revisão. Rev. bras. saúde ocup., 30(112), 69-79.

Morgan, R.; Mcdonagh, P.; \& Morgan, T. R. (1995). Employee job satisfaction: an empirical assessment of marketing managers as an occupationally homogeneous group, Journal of Managerial Psychology, 10(2), 10-17.

Murad, M. M. I.; Zayed, N. M.; \& Mukul, A. Z. A. (2013). A study on job satisfaction: focus on bankers of Bangladesh. European Journal of Business and Management, 5(17), 14-20.

Nodari, C. H.; Bó, G. D.; \& Camargo, M. E. (2010). Turnover e satisfação no trabalho em empresas multinacionais: um estudo de caso. Revista de Administração da Unimep, 8(2), $1-16$.

Oshagbemi, T. (1997). Job satisfaction profiles of university teachers. Journal of Managerial Psychology, 12(1), 27-39.

Oshagbemi, T. (1999). Overall job satisfaction: how good are single versus multipleitem measures? Journal of Managerial Psychology, 14(5), 388-403.

Oshagbemi, T.; \& Hickson, C. (2003). Some aspects of overall job satisfaction: a binomial logit model. Journal of Managerial Psychology, 18(4), 357-367.

Palomino, M. N.; \& Frezatti, F. (2016). Role conflict, role ambiguity and job satisfaction: Perceptions of the Brazilian controllers. Revista de Administração, 51(2), 165-181.

Pauli, J.; Tomasi, M.; Gallon, S.; \& Coelho, E. (2017). Satisfação, Conflitos e Engajamento no Trabalho para Professores do Ensino Médio. Revista Pensamento Contemporâneo em Administração, 11(4), 72-85. 
Penha, E. D. D. S.; Rebouçasa, S. M. D. P.; Abreua, M. C. S.; \& Parente, T. C. (2016). Percepção de responsabilidade social e satisfação no trabalho: um estudo em empresas brasileiras. Revista de Gestão, 23(4), 306-315.

Pinto, V. R. R.; \& Mariano, S. (2011). Satisfação no trabalho dos gestores escolares. Revista Pensamento Contemporâneo em Administração, 5(2), 110-125.

Silva, L. P.; Castro, M. A. R.; \& Dos-Santos, M. G. (2018). Influência da Cultura Organizacional Mediada pelo Assédio Moral na Satisfação no Trabalho. Revista de Administração Contemporânea, 22(2), 249-270.

Siqueira, M. M. M. (2008). Medidas do Comportamento Organizacional: Ferramentas de diagnóstico e de gestão. Porto Alegre, Bookman.

Tamayo, A. (1998). Valores organizacionais: sua relação com satisfação no trabalho, cidadania organizacional e comprometimento afetivo. Revista de Administração, 33(3), 5663.

Triviños, A. N. S. (1987). Introdução à pesquisa em ciências sociais: a pesquisa qualitativa em educação. São Paulo, Atlas.

Vergara, S. C. (2016). Projetos e relatórios de pesquisa em administração. (16a ed), São Paulo, Atlas. 